\title{
Nueva aproximación a la semántica de $I R$ en gallego: contribución a un diccionario analítico de construcciones
}

\author{
Xosé Soto Andión (Vigo, Spain)
}

\begin{abstract}
This article is based on our research about intransitive syntactic-semantic schemes and on our studies about the production of an analytical dictionary of structures for the Galician language. It centres on schemes with ir nucleus, schemes which imply actions with movement, process, states and other events. Some of the constructions presented can have equivalent structures in different Iberian romance languages; others are examples that are exclusive to the Galician. The results obtained can also be the basis for other contrastive or comparative projects and for the production of conventional and structural dictionaries.
\end{abstract}

\section{$1 \quad$ Introducción}

Esta investigación aborda los valores semántico-sintácticos de ir modelando un prototipo de diccionario de construcciones para el gallego, que mutatis mutandis se puede aplicar a otras lenguas ${ }^{1}$.

Desde el punto de vista sintáctico, nos estamos refiriendo a un predicado, que funciona en construcciones de contenido muy variado, algunas exclusivas del gallego, otras con similitudes en romances próximos. Convencionalmente solía enmarcarse en el grupo de los llamados verbos de movimiento.

Con la presente investigación, además de ofrecer dicho prototipo de diccionario de construcciones, pretendemos analizar los usos y valores de las construcciones con ir así como comprobar o certificar lo siguiente:

(i) Que estas construcciones van más allá de las acciones y del movimiento, lo que dificulta su adscripción a una única clase al participar en diversos esquemas y subclases semánticos.

(ii) Que resulta de gran utilidad el considerar la interfaz léxico, semántica y sintaxis para el estudio de la construcción, en particular, y para la investigación gramatical, en general.

(iii) Que es operativo trabajar con nuevos papeles semánticos diferentes de los convencionales (situado, caracterizado, portador de actitud/conducta, portador de relación), con el fin de elaborar análisis más rigurosos y precisos de las funciones semánticas y de la construcción.

\footnotetext{
1 Me han resultado de gran utilidad los datos bibliográficos que he podido reunir en la estancia de investigación realizada en la Universidad de Oxford, en el Research Centre for Romance Linguistics, estancia financiada por la Xunta de Galicia entre agosto-octubre de 2008 y septiembre-octubre de 2009.
} 


\section{Sobre los diccionarios de construcciones}

La elaboración de diccionarios de construcciones en gallego no fue objeto de atención por parte de los lingüistas (exceptuando una pequeña contribución de Riveiro 2002), de ahí que, a diferencia de otras lenguas, casi no existan.

A pesar de su carácter especializado, un diccionario de construcciones es una obra práctica. De ella puede sacar provecho cualquier estudiante nativo o extranjero, todo profesional que trabaje con la palabra y todos los lingüistas sin excepción: a los lexicógrafos les ayuda a componer las definiciones de manera más precisa e íntegra, a los gramáticos les sirve de apoyo en la preparación de gramáticas y otras monografías sobre sintaxis o semántica. También los traductores, profesores de idiomas y estudiantes de segundas lenguas se pueden beneficiar de distintas maneras, como por ejemplo comprobando determinadas regencias preposicionales o verificando la exigencia de sujetos [tanimados].

Conviene recordar que buena parte de los denominados diccionarios de construcciones son, en realidad, diccionarios únicamente de regencias verbales, verbos seguidos de preposiciones, en general de carácter más sintético que analítico. Algunos no proporcionan definiciones, aunque otros son explicativos y más completos, por eso hay que tenerlos en cuenta a la hora de elaborar una obra de estas características. Entre estos últimos podemos destacar el clásico Diccionario de construcción y régimen de la lengua castellana, de Cuervo (1953), para el español; los Französisches Verblexikon (1983) y Dicionário sintáctico de verbos portugueses (1994), de Busse, para el francés y portugués; ciertos diccionarios de valencias como los clásicos Wörterbuch zur Valenz und Distribution deutscher Verben, de Helbig/Schenkel (1991), y Verben in Feldern. Valenzwörterbuch zur Syntax und Semantik deutscher Verben, de Schumacher (1986) así como el más reciente Valenzwörterbuch deutscher Verben (2004), para el alemán; y por último el Diccionario sintáctico del verbo inglés, de Franciso Garrudo (1991) y el Valency dictionary of English de Thomas Herbst (2004), para el inglés.

Por tanto, un diccionario de construcciones es una obra necesaria porque también lo es la información semántico-sintáctica que proporciona, muy útil incluso en los diccionarios convencionales de léxico. En este sentido afirma Azorín Fernández (2003: 50-51) que "ni la sintaxis puede formular explicaciones significativas acerca de los diferentes tipos de construcciones sin tener en cuenta la semántica combinatoria de las piezas léxicas que podrían formar parte de aquellas ni, a la inversa, en la descripción del léxico se puede prescindir de los entornos sintácticos de las palabras [...] Si uno de los objetivos básicos del diccionario consiste en deslindar todas las acepciones de las piezas léxicas, no cabe duda de que las diferencias que revelan los entornos sintácticos pueden constituir una pauta clara para que el lexicógrafo lleve a cabo ese fundamental objetivo. Además es tarea del diccionario explicitar al usuario esas mismas acepciones de manera que este no sólo pueda identificarlas en los textos, sino también utilizarlas de manera adecuada cuando lo necesite. Para ambos cometidos, resulta útil (a veces incluso imprescindible) proporcionar información sobre los entornos sintácticos directamente ligados a las acepciones que se están deslindando".

En cuanto a la relevancia de la información semántico-sintáctica, podría pensarse que su uso convierte el diccionario en una obra inaccesible para el lector medio y lo limita a un público especializado. Ciertamente ese será el usuario que más provecho obtenga de estos contenidos, pero no debemos de olvidar que resulta igual de especializado proporcionar, como hacen algunos diccionarios convencionales, información etimológica, fonética, ciertos contenidos gramaticales y anotaciones referidas a verbo pronominal, transitivo e intransitivo. A este respecto afirma Seco (1995: 30) que "el simple hecho de asignar a un verbo la etiqueta transitivo o intransitivo implica la suposición de que el lector tiene unas nociones de sintaxis que, según mi experiencia, no suelen ocupar un lugar en la cabeza del ciudadano medio. Lo 
que ocurre es que el lector va derecho a las definiciones y se contenta con que estas le ayuden a interpretar la palabra que no entendía".

Así pues, un nuevo paso en la elaboración de diccionarios lo constituye la realización de diccionarios de construcciones, sobre todo de dimensión analítica, ya que debido a su carácter explicativo, descriptivo-analítico, esto es, de definición y ejemplificación a partir de un corpus de lengua oral y escrita, y de análisis de estructuras, se convierte en una obra de mayor amplitud y profundidad en lo que respecta a la información gramatical y estructural facilitada.

A continuación presentamos una ficha con la microestructura del diccionario analítico de construcciones, que concretaremos empíricamente estudiando la semántica y combinatoria de ir, partiendo de una lengua romance como es el gallego.

\section{Verbo-predicado}

1. Subentrada

Significado de acuerdo con cada construcción

i) Ejemplos (lengua escrita con obra y página, lengua oral con lugar y edad del informante ${ }^{2}$ ) Esquema sintáctico y esquema semántico ${ }^{3}$

- SUJETO [principales características sintácticas y semánticas según la construcción]

- COMPLEMENTACIÓN ${ }^{4}$ [principales características sintácticas y semánticas: tipo y subtipo de unidad, grado de obligatoriedad, estructura, orden ${ }^{5}$, rasgos semánticos, participantes opcionales...] - OTRAS CARACTERÍSTICAS DE LA CONSTRUCCIÓN: voz ${ }^{6}$, valor pronominal y uso de se, significado; distintos valores que sean pertinentes (tipo de acción o proceso, perífrasis, persona, tiempo, modo, número, negación...). Valores aspectuales ${ }^{7}$.

\footnotetext{
${ }^{2}$ Las muestras no numeradas proceden de anotaciones manuscritas y de nuestra competencia como hablantes.
}

3 Entendemos por esquema sintáctico la forma o esquema de funciones sintácticas desempeñadas por los argumentos o participantes de la construcción y por esquema semántico los diversos moldes que agrupan los papeles semánticos (para otros "papeles temáticos", cf. Primus 1999) ejercidos por dichos participantes. Manejar este parámetro supone distinguir esta clase de diccionario de otros muchos que no contemplan tal información. Nuestra posición a este respecto es maximalista, es decir, nos servimos de un variado conjunto de esquemas y papeles semánticos que dan cuenta con mayor exactitud de los múltiples eventos transmitidos por las construcciones. Es una posición que diverge de otras que se sirven de un número muy reducido de esquemas y papeles semánticos. Dik (1997: 12) comentaba, en relación con las funciones semánticas, que no constituyen una lista cerrada y que no está seguro de que resulten suficientes para recoger la diversidad de contenidos transmitidos por ejemplo a través de las preposiciones. En cualquier caso, alguno de los papeles semánticos que utilizamos puede encontrarse también en autores como, entre otros, Halliday (1994: 109 ss.), Dik (1997: 105 ss.), Van Valin/Lapolla (1997: 140 ss.), Álvarez/Xove (2002: 74-76), Moreno Cabrera (2003: 231 ss.).

${ }^{4}$ La complementación alude a las distintas funciones sintácticas de la construcción que precisan otras funciones básicas como son el sujeto y el predicado.

${ }^{5} \mathrm{El}$ orden prototípico del complemento es el posverbal y pospuesto al sujeto. Pero puede verse alterado por factores como la tematización y el semantismo de la construcción, que engloba tanto el significado léxico del verbo predicado como los valores aspectuales, la modalidad clausal, la voz, la animación y el control.

6 Manejamos tres tipos de voz: activa, media y pasiva. En la voz activa un agente actúa sobre una entidad "afectándola", en la pasiva una entidad se ve afectada por un evento. En ambas la dinamicidad tiene un punto de partida diferente, al igual que la estructura informativa y el orden. Con todo, la construcción no marcada parece ser la activa, y la pasiva, menos frecuente, se define a partir de aquélla; como dice Comrie (2008) puede haber activa sin pasiva pero no pasiva sin consideración de una activa. La voz media está formada por estructuras formalmente activas y por estructuras pronominales con se (vid. también Cidrás 1991; Mendikoetxea 1999; Ritter/Rosen 2000; Sánchez López 2002; Alexiadou/Anagnostopoulou/Everaert 2003; Ackema/Schoorlemmer 2006), presenta un sujeto afectado, que puede ser [+animado], sin consideración de un agente que realice la acción, aunque pueda existir un causante. Halliday/Mathiessen (2004: 280-305) aproximan la voz media a un tipo de cláusulas que actúa preferentemente bajo el patrón del denominado modelo ergativo y cuyo sujeto tiene un papel semántico de medium. Su presencia, al igual que el carácter semántico del verbo y de la construcción favorece en muchos casos la posposición del sujeto (Baltin 2003: 226-254) 
Un verbo del tipo de ir es un predicado de construcción que dará lugar a una entrada de diccionario, con sus correspondientes acepciones o construcciones. Organizar por palabras no es óbice para que la base teórica y analítica sea la construcción más que el verbo como clase de palabra, lo que ocurre es que la ordenación por verbos, que son predicados, facilita la consulta o lectura. Tomamos como base teórica la construcción y algunos principios cognitivistas en una línea próxima a la de, entre otros, Goldberg (1995, 2006), Croft (2001), Borer (2004), Van Valin (2005), Jackendoff (2007), Langacker (2008), en el sentido de situar la interrelación de los elementos de la estructura clausal como eje del análisis gramatical, pues las funciones sintácticas y los papeles semánticos están determinados tanto por el verbo predicado como por los demás participantes que cohesionan la secuencia que se constituye en construcción. La presencia de los distintos participantes de una secuencia es relevante para hablar de construcción, no sólo el verbo (aunque este sea el participante más destacado), pues los nombres, los adjetivos y las preposiciones también pueden necesitar un complemento o un modificador en forma de frase o cláusula (v.g. A nai de Pepe; fiel ás súas ideas; listo para actuar; contra o país), algo que ocurre de igual modo en otras lenguas ("a good book to read is hard to find", cf. Landau 1999: 333-359). Una óptica parecida adoptaba Halliday (1967: 38) al defender lo siguiente: "transitivity is concerned with the type of process expressed in the clause, with the participants in this process, animate and inanimate, and with various attributes and circumstances of the process and the participants" y también por este camino iban las afirmaciones de Hopper and Thomson (1980: 251): "Transitivity involves a number of components [...]. These components are all concerned with the efecctiveness with which an action takes place, e. g. the punctuality and telicity of the verb, the conscious activity of the agent, and the referentiality and degree of affectedness of the object".

Desde una perspectiva estrictamente semántica, ir es una unidad léxica que aparece en un marco semántico que permite construir su significado y, por tanto, comprenderlo de acuerdo con las construcciones sintácticas gobernadas por dicha unidad léxica. Es en esta línea en la que se sitúa la semántica de marcos ("frame semantics") de Fillmore (2006), cuyos presupuestos orientan también parte de nuestra investigación. Los análisis semánticos no parten aquí de un conjunto reducido de roles semánticos, como por ejemplo agente, paciente, destinatario, etc., porque la semántica de marcos de Fillmore ya ha puesto de manifiesto la dificultad de realizar un análisis semántico del léxico partiendo de este planteamiento. El problema está en determinar cuál debe ser la amplitud que deben tener los marcos, lo que significa para nosotros hablar de los límites de la taxonomía de los papeles y esquemas semánticos. En principio, los autores barajan la utilización de grandes escenarios semánticos, como por ejemplo movimiento, emoción, cognición, etc., algo parecido a clases semánticas generales de taxonomía amplia, como aquí defendemos.

En definitiva, la complejidad de los problemas asociados a la semántica de los eventos se concreta en diversas teorías y modelos aplicables a la semántica y a la sintaxis de la construcción. Si bien el principal "problema" de algunas teorías es que están elaboradas casi en exclusiva desde o para el inglés, por lo que no tenemos la certeza absoluta de que puedan ser aplicables en su totalidad a las restantes lenguas, a nosotros nos servirán de base teórica para estudiar el comportamiento de un verbo como $\mathrm{ir}$.

\footnotetext{
7 En valores aspectuales o aspectualidad (De Miguel 1999; Dimitrova-Vulchanova 1999; Bertinetto/Delfitto 2000; Thieroff 2000) incluimos tanto el aspecto léxico o aktionsart -modo del evento- derivado del lexema verbal en función de predicado, como el aspecto gramatical derivado de procedimientos morfológicos y sintácticos: sujeto y complementos, presencia de se, perífrasis, negación, adverbios y locuciones adverbiales, tiempos verbales, afijos derivativos y flexivos, etc. Dentro de estos valores y siguiendo a los autores antes mencionados discriminamos los contenidos de estativo/dinámico, puntual/durativo o progresivo, atélico/télico, simple/iterativo (múltiple e intermitente), habitual, permanente, no intensivo/intensivo/atenuativo.
} 


\section{$3 \quad$ Los tipos de eventos}

Ir funciona como predicado de construcciones que manifiestan, como veremos, diversos tipos de eventos: acción, estado, proceso, relación, actitud/conducta.

Las acciones indican actividad y dinamismo, de tipo físico o mental, de una persona o de una entidad (los que la tradición denomina agentes y fuerzas). Podemos decir que "activities, like states, are atelic, but unlike states, they are dynamic" (Rothstein 2004: 17). La acción es un macropapel genérico que por su versatilidad puede solapar o asimilar distintos eventos, entre ellos el movimiento.

El estado es un macropapel semántico que, por lo general, se aplica a condiciones que carecen de desarrollo temporal interno; podemos hablar de su duración, pero no de su progreso o culminación. Como dice Rothstein (2004: 14): "states or stative eventualities are cumulative and non-dynamic, i.e. [-telic, -stages]. They are also totally homogeneous". Los estados designan la condición de una entidad o individuo, situaciones (v.g. Está en Santiago), caracterizaciones -características o propiedades (está moi guapa)- atribuídas a dichas entidades o individuos cuyo papel semántico es el de situados, portadores de estado y caracterizados (cf. Soto Andión 2011). También pueden considerarse estados las construcciones de posesión (v. g. A casa perténcelle a seu pai; a carteira é del), de existencia y de dimensión espacial o temporal (v. g. A estrada vai ata Vilagarcía).

Los procesos representan el tránsito de un estado a otro protagonizado por un individuo o entidad (experimentantes). Los procesos pueden ser de diversas clases según el cambio experimentado por la entidad sujeto en relación con una determinada propiedad o cualidad. En ocasiones una misma estructura implica simultáneamente dos procesos paralelos o superpuestos, de este modo "enfraquecer" puede mostrar un valor diminutivo y a la vez empeorativo.

Relacionado con estas clases están las que llamamos de actitud/conducta y de relación. La primera es una clase semántica que conforma construcciones en las que funciona un sujeto que ejerce el papel semántico de portador de actitud/conducta (cf. Soto Andión 2005). Esta clase puede participar en construcciones de valor aspectual tanto estativo como dinámico, lo que significa que puede funcionar a la par de o superpuesto a un estado o a una acción. Existen estrechas relaciones entre actitudes y conductas, pues se trata de eventos muy próximos, el primero de carácter más psíquico que el segundo. Perloff (2003: 36 ss.) defiende la influencia de las actitudes en las condutas y en las acciones. Nosotros consideramos la actitud como la postura corporal y la disposición anímica adoptada por la entidad sujeto ante alguien o ante algo, y la conducta como un modo de comportarse y de conducirse. A partir de aquí, vemos que los límites entre actitudes y conductas no siempre resultan nítidos y evidentes en la lengua, por eso el papel semántico que las representa ha de corresponderse con este hecho y denominarse portador de actitud/conducta (siguiendo la línea maximalista que defendemos para los papeles semánticos).

En cuanto a la clase semántica que llamamos relación, los diccionarios la definen así:

- "1. Aquilo que liga dous ou máis elementos entre si, que fai que dous ou máis elementos teñan algo que ver entre si" [Diccionario da Real Academia Galega 2012].

- "A 2. Caractère de deux ou plusieurs choses entre lesquelles existe un lien. 3. Liaison entre deux points géographiques. B.1. Lien de dépendance ou d'influence réciproque (entre des personnes). 2. Connaissance, fréquentation d'une personne. 3. Personne avec laquelle on est en relation, on a des relations d'habitude, d'intérêt. C. Tout ce qui, dans l'activité d'un être vivant implique une interdépendance, une interaction". [Le Petit Robert 2006: 2226]. 
A partir de aquí, uno de los distintos subtipos semánticos que podemos establecer, perteneciente tanto a la clase de las acciones como a la de los estados, es el referido a aquellas construcciones que indican relación, en la línea del significado arriba señalado. En estas construcciones el sujeto tiene asignado el papel semántico de portador de relación, un papel que refiere el individuo o entidad que manifiesta alguna relación (trato, conexión, correspondencia, comunicación...) con algo o alguien.

Todas estas clases representan categorías semánticas, que pueden recategorizarse unas en otras (Carpenter 1997), lo que significa que un mismo predicado es capaz de funcionar en esquemas semánticos diferentes (cf. Soto Andión 2008): "María anda" es una acción que implica movimiento, "María xa anda" [porque tiene un año] comporta la adquisición de una determinada propiedad, habilidad; "vou pola ponte de Tui" expresa la acción-movimiento de un agente, en cambio "vou guapo" es un estado.

Algunas de estas clases destacan por su alta representatividad, como sucede con las acciones o actividades y, dentro de estas, con el subtipo que constituye el movimiento (cf. Soto Andión 2010a, b), en el cual acostumbran a incluirse las construcciones nucleadas por $i r$. La tipología del movimiento la reproducen diversos autores como, entre otros, Tesnière (1959), Talmy (1985, 2000), Lamiroy (1991), Cifuentes (1999), Crego (2000), Morimoto (2001), Slobin (2004, 2006).

Tesnière diferenciaba un movimiento intrínseco relacionado con las condiciones somáticas del sujeto (para recorrer una cierta distancia el hombre anda, el pez nada, el pájaro vuela) de un movimiento extrínseco que tiene que ver con el espacio (arribalabajo, derecha/izquierda, delanteldetrás, ir/venir...).

Talmy dice que los verbos de movimiento de las diferentes lenguas pueden clasificarse en dos grandes clases, a saber: los "verb framing" y los "satellite framing" (con módulo de trayectoria). Al primer grupo pertenecen las lenguas romances, al segundo el inglés. Afirma además que las diferentes expresiones que reflejan una trayectoria obedecen a microparámetros asociados al contenido de las preposiciones, que interaccionan con el valor aspectual de los verbos de movimiento.

Lamiroy habla de desplazamiento centrado en el espacio (con pares direccionales como $\mathrm{ir} / \mathrm{vir}$, entrar/saír, subir/baixar...), modo de desplazamiento centrado en el sujeto (con verbos como camiñar, nadar, correr, fuxir...) y movimiento corporal o cambio de postura (volverse, sentarse, axeonllarse...). En la misma línea, Crego discrimina, dentro de las construcciones de movimiento, las que expresan desplazamiento y las que designan modo de desplazamiento. Clasifica los verbos de movimiento en causativos, que son los que indican desplazamiento direccional (dirixirse, subir, baixar...), situacional (erguerse, deitarse, sentarse, volverse...) o modo de desplazamiento (pasear, voar...)-, y no causativos que a su vez pueden señalar desplazamiento direccional (ir, vir, saír, caer...) o modo de desplazamiento (andar, camiñar, nadar...). Unos y otros comportan una serie de combinaciones y restricciones, según los contenidos y los esquemas en los que funcionen.

Morimoto relaciona el comportamiento sintáctico de los verbos con su significado léxico. A partir de aquí centra su investigación en los verbos de movimiento no causativos, que son a) verbos de desplazamiento (ir, vir, entrar, saír, subir, baixar, afastarse, achegarse, partir, chegar, cruzar...), que poseen una trayectoria determinada; b) verbos de manera de moverse, que hacen referencia al modo de moverse; son del tipo 1 (camiñar, andar, correr, nadar, pasear, voar...) y expresan un desplazamiento o trayectoria indeterminada; y del tipo 2 (tremer, axitarse, ondear, patalear, balancearse...), que no expresan ninguna trayectoria sino un movimiento interno al objeto. 
Slobin (2004) habla de lenguas de marco equipolente o equivalente, que expresan la trayectoria y la manera sirviéndose de medios idénticos, como ocurre en las lenguas de verbos seriales en las que un verbo codifica la manera y otro la trayectoria, en las lenguas de verbos bipartitos, en las que el verbo posee dos morfemas, uno que expresa manera y otro trayectoria, $\mathrm{y}$ en las lenguas de verbos funcionales o genéricos en las que existe un verbo general junto a varios preverbos de manera y de trayectoria.

\section{Semántica y combinatoria de ir}

A continuación vamos a centrarnos en algunas construcciones prototípicas nucleadas por este predicado, tomando como base la semántica o variabilidad de eventos que transmiten las estructuras nucleadas por este verbo.

\subsection{Ir como predicado de acción}

Este grupo comprende construcciones mayoritariamente de uno y dos participantes. Ocasionalmente hemos registrado alguna construcción de cero y de tres participantes. La acción con frecuencia se concreta en algún tipo de movimiento, con o sin desplazamiento propiamente dicho.

\section{Desplazarse hacia un lugar caminando o en un medio de transporte}

1. toda a nuite tragh do carneiro e o carneiro non ía prá casa (MAZARICOS-A Coruña, 46)

2. non teño morriña de Ourense, de vez en cando tamén vou alí (OURENSE, 27)

3. Rosa foi á parte da cociña e volveu cun cazo (ESC, 155)

4. episodio gracioso acontecido naquela viaxe, protagonizado por unha señora que ía no autobús (DEUS, 149)

5. Se cansas imos máis a modo (OCT, 184)

Esquema sintáctico sujeto-predicado-circunstancial. Esquema semántico agente-accióndirección, modo...

Sujeto preverbal. Sus rasgos semánticos son [+animado] y [thumano], [+concreto], [+común], [+control], [-control] tratándose de entidades no humanas en las que el control no depende únicamente del sujeto sino de un causante [+humano].

La complementación es obligatoria. A veces puede no explicitarse por ser conocida a través del contexto o de otros referentes del mensaje. Funciona un circunstancial representado por una frase adverbial que señala destino, y una frase preposicional de estructura cara $a$, en dirección $a$, para ...+fr.nom. indicando dirección; a+fr.nom. señalando destino; ata+fr.nom. señalando punto límite del desplazamiento; a través de, por +fr.nom. reflejando tránsito; de, dende+fr.nom. indicando origen o punto de partida. Otros papeles semánticos son los de posición (v.g. Vou diante de ti), medio -fundamentalmente un medio de transporte-, comitativo (v. g. Foi connosco a Lugo), orden (v. g. Foi a Lugo primeiro). El complemento se sitúa en posición posverbal, pero no es inusual la anteposición de la frase preposicional (v.g. Pero elas así coma agora á taberna non ían). En cambio, resulta poco aceptable la anteposición de la frase adverbial en contextos de estas características (v. g. * De vez en cando alí vou) a no ser que se introduzca otra partícula (v. g. De vez en cando alí tamén vou).

La construcción es de voz activa. Señala un movimiento con desplazamiento. Admite se para indicar sujeto indeterminado y para intensificar la presencia del agente en el movimiento de partida. Los valores aspectuales son dinámico, télico, inceptivo con se; ocasionalmente habitual, iterativo, intermitente.

Estos esquemas pueden encontrarse en lenguas vecinas próximas como portugués y español (v. g. Carlos viaja e eu vou também; foi-se naquela direção; fui a Vigo; vou para Porto; Voy a Santiago; vamos más despacio; fue a la cocina). 


\section{Desplazarse a un lugar con una finalidad concreta}

6. ahora xa van pá taberna toma-lo café con leite (SOUTELO-Forcarei-Pontevedra, 60)

7. e fun á barbería para que o Leonardo me fixera un bon afeitado (BE, 264)

8. fume pa Lugo, fume facer os exámenes de ingreso (POL-Lugo, 68)

Esquema sintáctico sujeto-predicado-circunstancial-circunstancial. Esquema semántico agente-acción-dirección-fin.

Sujeto preverbal. Sus rasgos semánticos son [+animado] y [+humano], [+concreto], [+común], [+control].

La complementación resulta obligatoria. Funciona un circunstancial que es una frase preposicional de estructura $a$, para+fr. nom., señalando la dirección y el punto de destino del desplazamiento de un individuo. Un segundo complemento está representado por una cláusula introducida por para que, con verbo en forma personal, o por una frase preposicional de estructura $a$, para+cláusula de infinitivo, señalando la finalidad del desplazamiento. Si suprimimos el complemento de lugar y dirección, la estructura se sitúa en los límites de la construcción perifrástica con valor de intencionalidad (v. g. Vai tomar o café).

La construcción es de voz activa. Admite la presencia de un clítico variable en número y persona reforzando la idea de marcha y partida del individuo representado en el sujeto. No se usa negación delante del infinitivo, aunque sí se puede utilizar ante el verbo de movimiento (v. g. Non me fun para Lugo facer os exames/"funme para Lugo non facer os exames/"fun non facer os exames). Los valores aspectuales prototípicos son dinámico, télico; a veces se marca un valor inceptivo.

Se documenta también en lenguas próximas como portugués (v. g. Vamos vestir-nos para saír; fui a Lisboa estudar) y español con a (v.g. Vamos a prepararnos para salir).

Desplazarse para realizar un determinado trabajo o ir en busca de algo o alguien

9. o crego e maila criada foron ós garabulliños (TORDOIA- A Coruña, 83)

10. os domingos pola mañá mentres os demais ían na misa sentabamos nuns tallos na eira (ESC, 99)

11. aínda saliches o domingo pasado ou non fuche á follateira (LUÍNTRA-Ourense, 21)

12. ó outro día con medo e todo xa se foi ó mare (SADA-A Coruña, 70)

13. o Mauser terciado coma quen vai aos coellos (BE, 263)

14. esperade aquí, que vou polo coche (SANTIAGO, 38)

15. vai buscar un carneiro e despois quéntaste. E foi por un carneiro (VERÍN-Ourense, 70)

16. eran os carabineiros daquela época, que eran os que iban detrás del pois andaban sejido detrás da muller (NOIA-A Coruña, 26)

Esquema sintáctico sujeto-predicado-circunstancial. Esquema semántico agente-accióndestino.

Sujeto preverbal. Sus rasgos semánticos son [+humano], [+concreto], [+común], [+control].

La complementación es obligatoria. Aparece un circunstancial, cuya función desempeña una frase preposicional, de estructura $a+$ fr.nom., que indica dirección y destino, en+fr.nom. señalando lugar, acto, actividad, etc. en los que se está, y detrás de, por+fr.nom., con referente [tanimado], designando meta, destino y en ocasiones la causa última del desplazamiento. Opcionalmente puede acompañar algún otro circunstancial con el papel semántico de locación espacial y temporal, modo, comitativo, orden, causa, fin (v. g. Foi con ela á leña para o lume), condición... A veces se registra un dativo con el papel semántico de afectado, beneficiado/perjudicado (v.g. Funlle á madeira) y un predicativo del sujeto (v.g. Foi contento aos cogumelos; foille contento polo coche). 
La construcción es activa y refleja un movimiento con desplazamiento. Admite se para indicar sujeto indeterminado. Puede señalar un agente que se desplaza para traer algo que es de su posesión o con la idea de buscar (a veces con ansia) algo o a alguien que ha huido, se ha perdido o que no se posee pero se desea tener (v. g. Ían todos detrás da medalla de ouro). Los valores aspectuales son dinámico, télico o atélico según se manifieste o no fin y duración , a veces habitual (v.g. Vai á misa todos os días).

Esta estructura puede encontrarse en español, a veces con $a$ a diferencia del gallego (v.g. Voy a por el coche). En portugués acostumbra a usarse el infinitivo (v. g. Vou buscar o pão) frente a (v. g. Vou polo pan/voy a por el pan).

\section{Marcharse, abandonar un lugar, salir}

17. tanto andas voume, voume, xa te puideches ter ido (OUROL-Lugo, 84)

18. vaite, viaxeiro, non queiras coñecer Torre de Kerjean (BE, 25)

Esquema sintáctico sujeto-predicado. Esquema semántico agente-acción.

Sujeto preverbal. Sus rasgos semánticos son [+animado] y [thumano], [+concreto], [+común], [+control].

La complementación no es obligatoria. Puede aparecer algún dativo de interés (v. g. Váiteme de aquî) o un circunstancial con el papel semántico de locación temporal o espacial, a veces reforzando el punto de partida y el momento (v. g. Empinxa, repinxa vaite de aquí, cenza do lar anda atrás de ti), causa, fin, modo (v. g. Voume rapidamente), comitativo, condición (v.g. Sen a túa axuda iríanse cedo)...

La construcción es activa, con un clítico variable en número y persona que vuelve innecesaria la existencia de complemento. Esta construcción es muy utilizada en tiempos de imperativo, en la modalidad exhortativa cuando un emisor se dirige a un interlocutor para conminarlo a abandonar el lugar en el que está. Los valores aspectuales son dinámico, télico; el clítico puede acentuar el valor inceptivo.

Otras lenguas ibéricas como portugués y español conocen esta construcción y pueden usar clítico (v. g. Foi-se logo que caiu a noite; se fue en cuanto amaneció). En portugués con para suele adquirir valor de permanencia en el destino (v. g. Vou para Paris).

\section{Moverse de forma genérica e indeterminada o en una atracción}

19. Se vai, vai e se non vai queda (NOIA-A Coruña, 76)

20. tropesan nun e tropesan en calquera porque non ven cando van (NOIA-A Coruña, 76)

21. ese día tamén vou nas barcas (CERDEDO-Pontevedra, 10)

Esquema sintáctico sujeto-predicado, sujeto-predicado-circunstancial. Esquema semántico agente-acción, agente-acción-medio.

Sujeto preverbal. Sus rasgos semánticos son [+humano], [+concreto], [+común], [+control].

La complementación no es obligatoria en algunas estructuras y resulta obligatoria en otras como (21), en que aparece desempeñada por un circunstancial que indica el medio en el que alguien se mueve, en este caso para divertirse. Con carácter opcional pueden acompañar otros circunstanciales con diversos papeles semánticos como loc. espacial o temporal, causa, fin, modo y cuantificación (v. g. O neno vai moito nas barcas para se divertir), adición (v. g. Vai nas barcas ademais de na montaña rusa), sustitución (v. g. Vai nas barcas en lugar de na montaña rusa)...

Existe esta construcción en portugués y español (v.g. Vou de cá para lá; Carlos viaja e eu vou também; voy de acá para allá; fui en el carrusel). El portugués se vale de la estructura ir de+frase nominal (v. g. Ir de trem). 


\section{Pasar siendo señalado por alguien}

22. Mira, ai o vai (LOUREIRO-Cotobade-Pontevedra, 80)

23. Velaí a vai, xusto á hora que che dixen (CACHAFEIRO-Forcarei-Pontevedra, 40)

Esquema sintáctico sujeto-predicado-circunstancial. Esquema semántico agente-acciónloc. espacial, tránsito.

Sujeto posverbal por centrarse a menudo la información en el complemento, que generalmente es de carácter adverbial. Sus rasgos semánticos son [+animado] y [+humano], [+concreto], [+común], [+control].

La complementación es obligatoria. Funciona un circunstancial representado por una frase preposicional o adverbial. Aparece con frecuencia un pronombre, variable en género y número, referido al sujeto, en ocasiones con valor despectivo; resulta habitual cuando el emisor busca llamar la atención del interlocutor sobre alguien a quien ve pasar. Con carácter opcional pueden acompañar otros circunstanciales con el papel semántico sobre todo de locación espacial, dirección, loc. temporal, modo (v. g. Aí a vai agora para a casa correndo).

La construcción es activa y refleja un desplazamiento. Admite se para indicar sujeto indeterminado. Los valores aspectuales son dinámico, atélico.

Asistir a un determinado acontecimiento, acto, etc.

24. fóronme á miña voda máis de cincuenta mozos e mozas (SOUTELO-Forcarei-Pontevedra, 60)

25. as nenas das Casas Novas van todas xuntas á misa (SANTIAGO, 78)

26. meus primos foron todos á escola aquí (PONTEDEUME-A Coruña, 41)

Esquema sintáctico sujeto-predicado-circunstancial. Esquema semántico agente-accióndestino.

Sujeto preverbal. Puede posponerse al predicado cuando el emisor centra su atención informativa en el evento o en el complemento. Sus rasgos semánticos son [+humano], [+concreto], [+común], [+control].

La complementación es obligatoria. El circunstancial está representado por una fr. prep. de estructura $a+f r . n o m .$, con referente [-animado], que señala el acontecimiento, actividad, etc. al que alguien asiste. Con carácter opcional acompaña un dativo y/o complemento indirecto, con el papel semántico de beneficiado/perjudicado así como algún circunstancial con papeles semánticos como los de loc. espacial o temporal, modo, causa (v. g. Non foron á festa ben preparados polas présas), fin, sustitución (v. g. Foron á festa en vez de á misa)...

La construcción es activa. Muestra un agente que se desplaza para asistir a algún tipo de acto. Puede registrarse con se indicando sujeto indeterminado. Los valores aspectuales son dinámico, télico, a veces habitual.

Esta misma estructura se documenta en español (v. g. Fui a tu fiesta) y en portugués (v. g. Fui à sua conferência).

\section{Ser enviada o remitida una cosa a alguien o a alguna parte}

27. a denuncia vai no xulgado (SANTIAGO, 78)

28. o contrato foi a Madrí (PONTEDEUME-A Coruña, 41)

29. ei che vai o desafio, nena do pano marelo (SANTIAGO, 78)

Esquema sintáctico sujeto-predicado-circunstancial. Esquema semántico afectado-accióndestino.

Sujeto preverbal. Puede posponerse cuando se tematiza un complemento. Sus rasgos semánticos son [-animado], [+concreto], con frecuencia [+común], [-control]. 
La complementación es obligatoria. Funciona un circunstancial representado por una frase adverbial o preposicional de estructura $a$, en+fr.nom., que señala un lugar como límite o destino. La frase preposicional introducida por en no resulta habitual en pretérito (v. g. " A denuncia foi no xulgado) ni es posible con se (v. g. "A denuncia vaise no xulgado), por lo que es el presente el tiempo no marcado en este contexto (v.g. A denuncia vai no xulgado/a denuncia vai ao xulgado). Con carácter opcional acompaña un dativo (v.g. Aí che vai a denuncia da que che falei), que explicita el individuo que ha de recibir la cosa enviada, y otros circunstanciales con diversos papeles semánticos como loc. temporal, modo, medio (v. g. A carta vai hoxe no xulgado por correo certificado), condición (v. g. Sen a túa axuda o contrato non iría a Madrid).

La construcción tiene forma activa y significado de carácter medio o pasivo (a denuncia vai no xulgado puede equivaler a foi enviada ao xulgado). La persona es la tercera y el agente se desconoce. Los valores aspectuales son dinámico, télico.

Puede documentarse en lenguas próximas como español (v.g. El certificado va a Vigo) y en portugués sin complementación (v. g. O recado já foi e a carta acaba de ir).

\section{Dirigirse a un lugar para intentar sustraer algo, robar}

30. tiña un sacristán que lle iba á caixa das ánimas e íballe tamén ó viño (FEÁS-Ourense, 49)

31. entráronlle na casa e fóronlle ós cartos (FORCAREI-Pontevedra, 50)

32. pa que o gato non vaia ó leite (SOBER-Lugo, 70)

Esquema sintáctico sujeto-predicado-circunstancial. Esquema semántico agente-accióndestino.

Sujeto preverbal. Puede posponerse debido a las prioridades informativas del emisor tematizando el complemento. Sus rasgos semánticos son [+animado], [+humano], [+común], [+control].

La complementación es obligatoria. Funciona un circunstancial representado por una fr. prep. de estructura $a+f$ fr.nom. y referente [-animado], que alude a aquello que alguien busca para sí. Va inmediatamente pospuesto al predicado o separado de él por algún argumento, con frecuencia un dativo, con el papel semántico de perjudicado. Opcionalmente acompaña algún circunstancial con distintos papeles semánticos como loc. temporal y frecuencia (v.g. Ílle aos cartos tódolos días), loc. espacial, modo y cuantificación, causa, fin...

La construcción es activa. Admite se para indicar sujeto indeterminado. Los valores aspectuales son dinámico, télico, a veces iterativo y habitual.

\section{Ejercer un determinado oficio o desempeñar una profesión}

33. o oficio de zapateiro non me daba e fume de canteiro (ACIVEIRO-Forcarei-Pontevedra, 78)

34. ós trece anos xa fun de peón da-lo barro a Lugo (ACIVEIRO-Forcarei-Pontevedra, 75)

Esquema sintáctico sujeto-predicado-circunstancial. Esquema semántico agente-acciónmodo.

Sujeto preverbal. Puede posponerse por las prioridades informativas del emisor al tematizar la acción. Sus rasgos semánticos son [+humano], [+concreto], [+común], [+control].

La complementación es obligatoria. El circunstancial está representado por una fr. prep. de estructura $d e+f r . n o m .$, sin determinante, que indica el tipo de profesión que alguien va a ejercer. Con carácter opcional acompaña un circunstancial con el papel semántico sobre todo de loc. espacial y destino, loc. temporal, causa (v. g. Daquela fun de canteiro para Lugo por necesidade), fin. 
La construcción es activa. Admite se para indicar sujeto indeterminado, otras veces para intensificar la participación del sujeto centrando en él el evento. Los valores aspectuales son dinámico, atélico.

En español existe esta estructura (v. g. Descartó ir de delegada).

\section{Pasar al siguiente curso}

35. cando fun para sesto xa non me gustaba tanto estudiar (VEDRA-A Coruña, 16)

Esquema sintáctico sujeto-predicado-circunstancial. Esquema semántico agente-accióndestino.

Sujeto preverbal. Sus rasgos semánticos son [+humano], [+concreto], [+común], [+control].

La complementación es obligatoria. El circunstancial está representado por una fr. prep. de estructura para+fr. nom., que indica el punto de destino de un movimiento de carácter nocional. De forma opcional aparece algún circunstancial con el papel semántico de modo, tiempo, causa... y algún predicativo del sujeto (v. g. Este ano foi contento para sexto).

La construcción es activa. Admite se para indicar sujeto indeterminado. Los valores aspectuales son dinámico, télico.

En español también se registra (v. g. Este año va para sexto).

\section{Realizar unos estudios, prepararse para una profesión}

36. a min dixérome que iba pa cura, non sei se é certo ou non (FREIXEIRA-ForcareiPontevedra, 70)

Esquema sintáctico sujeto-predicado-circunstancial. Esquema semántico agente-accióndestino.

Sujeto preverbal. Sus rasgos semánticos son [+humano], [+concreto], [+común], [+control].

La complementación resulta obligatoria. El circunstancial está representado por una fr. prep. de estructura para+fr.nom., que indica el punto de destino de un movimiento nocional. Opcionalmente acompaña algún circunstancial con el papel semántico sobre todo de modo, loc. temporal, causa... Más ocasional es un dativo (v.g. O fillo vaille para cura) y un predicativo del sujeto (v. g. Está indo convencido para cura).

La construcción es activa. Admite se para indicar sujeto indeterminado. Los valores aspectuales son dinámico, atélico.

Lenguas próximas como español y portugués manejan esta construcción (v.g. Va para ingeniero; vai para a engenharia).

Elegir, escoger una opción o ámbito de estudio y trabajo

37. Case todos foran pola Mariña, por aquel entón (BE, 14)

38. en terceiro fun por ciencias (LALÍN-Pontevedra, 18)

Esquema sintáctico sujeto-predicado-circunstancial. Esquema semántico agente-accióndestino/dirección.

Sujeto preverbal. Puede posponerse cuando el emisor tematiza el complemento (v.g. Pola Mariña non foron todos). Sus rasgos semánticos son [+humano], [+concreto], [+común], [+control].

La complementación resulta obligatoria. El circunstancial está representado por una fr. prep. de estructura por+fr.nom., con referente [-animado] que señala destino o dirección en el sentido de elección de profesión, estudios, etc., realizada por un individuo. De forma opcional puede acompañar un circunstancial con el papel semántico sobre todo de loc. temporal, espacial, modo, causa (v. g. Daquela fun por ciencias por un capricho), en menor medida un 
dativo (v.g. O rapaz vaille por artes) y un predicativo del sujeto (v. g. Vai convencido por humanidades).

La construcción es activa. Admite se para indicar sujeto indeterminado. Los valores aspectuales son dinámico, télico.

También se documenta regularmente en español (v. g. Va por ciencias).

\section{Funcionar, servir, valer una cosa}

39. o motor xa non vai, agora cansou (COVAS-Forcarei-Pontevedra, 40)

40. ¿Que, vai ou non vai? (ACIVEIRO-Forcarei-Pontevedra, 75)

Esquema sintáctico sujeto-predicado. Esquema semántico afectado-acción.

Sujeto preverbal. Puede posponerse en contextos, con frecuencia negativos, en los que se prioriza la información transmitida por el verbo (v.g. Non vai o motor). Sus rasgos semánticos son [-animado], [+concreto], [+común], [-control].

La complementación es obligatoria. De forma opcional puede registrarse algún complemento modalizador (v. g. Veña, agora $x a$ vai) y un circunstancial con el papel semántico sobre todo de modo (v. g. Vai ben), causa, medio (v. g. Con iso non vai).

La construcción tiene forma activa y significado de voz media. Se usa en P3 singular o plural. Con referente animado aparece la primera persona de plural, cuando el emisor pretende hacer partícipe de los hechos al interlocutor (v.g. A ver, como imos?). También se registra en la modalidad interrogativa con un el invariable (v.g. El vai ou non vai?). Los valores aspectuales son dinámico, atélico.

En español y portugués existen estructuras similares (v.g. El coche no va; não ir o veículo).

Vestir ropa adecuada o de un determinado tipo, color, etc.

41. cando se vai de festa gústame que a xente vaia ben (LOUREIRO-Cotobade-Pontevedra, 80)

42. os mozos daquela iban de traxe e corbata (FREIXEIRA-Forcarei-Pontevedra, 70)

Esquema sintáctico sujeto-predicado-circunstancial. Esquema semántico agente-acciónmodo.

Sujeto preverbal. Sus rasgos semánticos son [+humano], [+concreto], [+común], [+control].

La complementación es obligatoria. El circunstancial puede estar representado por una frase adverbial, frase adjetiva o frase preposicional, que indican un determinado modo de vestir. A veces funciona, con carácter opcional, algún otro circunstancial con el papel semántico de loc. temporal y espacial, fin, causa (v. g. Onte fun de traxe por causa do protocolo).

La construcción es activa. Puede usarse con se para indicar sujeto indeterminado. Los valores aspectuales son dinámico, atélico, en ocasiones iterativo y habitual (v.g. Vai de traxe a miúdo).

En lenguas próximas como el español también se registra (v. g. Va de uniforme y de corbata); el portugués cambia el predicado aunque mantiene la estructura (v. g. Está de uniforme e de gravata).

\section{Verse $o$ no afectado por una cosa, concernir o referirse algo a alguien}

43. a cousa non vai con eles (COVAS-Forcarei-Pontevedra, 38)

44. o que dixeron ali iba por el (COVAS-Forcarei-Pontevedra, 38)

Esquema sintáctico sujeto-predicado-complemento prepositivo. Esquema semántico agente-acción-término. 
Sujeto preverbal o posverbal (v.g. Con eles non vai a cousa). Las prioridades informativas del emisor y la no animación favorecen la posposición. El sujeto refiere un evento tratándose de una cláusula o es un nombre con los rasgos semánticos [-animado], [+concreto], generalmente [+común], [-control].

La complementación resulta obligatoria. El complemento prepositivo está representado por una fr. prep., de estructura con, por+fr.nom., con un referente [+animado] y [+común], que designa con la primera preposición la persona implicada o asociada a algo que se dice o a un hecho que ocurre, y con la segunda preposición la persona destino, aludida por algo que se dice o por un hecho que acontece.

La construcción es activa. Se usa en P3 singular o plural y sin se. Resulta habitual en contextos negativos cuando el emisor quiere negar su implicación o la de otra persona en algún hecho. Los valores aspectuales son dinámico, atélico, a veces intensivo.

En español existe esta estructura (v.g. Eso no va contigo), pero en portugués cambia (v.g. Isso não tem a ver contigo).

Gastarse algo, agotarse, consumirse, dejar de existir, y por extensión

morirse una persona

45. os cartos vanse de contado se non tes tino deles (SOUTELO-Forcarei-Pontevedra, 60)

46. o tempo vaise e non facemos nada (CERDEDO-Pontevedra, 60)

47. Foise a chuva de todo e o ceo ficou limpo (ARR, 25)

48. foise o noso amigo despois dunha grave enfermidade (GDXL, 1132)

Esquema sintáctico sujeto-predicado. Esquema semántico afectado-acción.

Sujeto preverbal. En cláusulas simples con nombres que señalan fenómenos naturales existe una tendencia a invertir el orden (v. g. Foise o sol; vaise a néboa). Sus rasgos semánticos son variables: [+animado] y [+humano], [-animado], a menudo [+concreto] y [+común], [+continuo], [-control].

La complementación no resulta obligatoria. Opcionalmente funciona algún circunstancial con el papel semántico sobre todo de modo, intensificando la rapidez con la que remata el evento descrito, loc. temporal, causa (v .g. A chuvia foise co verán).

La construcción es de voz media y forma pronominal, con un clítico que actúa como formante lexemático del verbo reforzando el papel de afectado del sujeto. Dando la vuelta a la estructura llegamos en ciertos casos a una construcción transitiva con presencia de un agente controlador (v.g. Os cartos vanse; a gasolina foise alguén gasta os cartos decontado; alguén gastou a gasolina). Los valores aspectuales son dinámico, télico.

En lenguas próximas como español también se registra (v. g. Se ha ido para siempre; se está yendo el verano). En portugués aparece con y sin clítico (v. g. Foi primeiro que a mulher; foise o verão).

\section{Perder algo o alguien el control, inclinarse}

49. fóiselle o trator e non o pudo dominar (COVAS-Forcarei-Pontevedra, 64)

50. íbase un pouco a lancha (SADA-A Coruña, 70)

Esquema sintáctico sujeto-predicado. Esquema semántico afectado-acción.

Sujeto posverbal cuando es un nombre común, aunque no ocurre lo mismo con un nombre propio o pronombre (v.g. ?íaselle ela e a pouco máis cae). Favorece esta posición el semantismo de la construcción con presencia de se, la no animación del sujeto y el funcionamiento de un dativo. Sus rasgos semánticos son [+animado], generalmente [+concreto], [+común], [-control]. 
La complementación no resulta obligatoria. En ocasiones aparece un complemento indirecto con el papel semántico de perjudicado, que a veces es también el causante involuntario (no intencionalidad) de la acción así como el poseedor de la entidad afectada. Puede encontrarse algún circunstancial con el papel semántico de causa, modo y cuantificación (v. g. Íaselle moito a cabeza co estrés).

La construcción es pronominal. Se usa en P3, con un clítico que actúa como formante lexemático del verbo y que otorga a la estructura un significado que la diferencia de otras en las que participa este mismo verbo. Los valores aspectuales son dinámico, télico; a veces iterativo (v.g. Váiselle moitas veces o coche nesa curva), intensivo, puntual (v.g. Fóiselle moito o coche na curva).

Otras lenguas próximas como el español tienen esta construcción (v. g. Se le fue el coche).

\section{Darse un determinado tiempo o condiciones atmosféricas}

51. non gustou nada da intemperie, que ía un frío que cortaba o alento (ESC, 32)

Esquema sintáctico predicado. Esquema semántico acción meteorológica.

La complementación es obligatoria. Con frecuencia aparece algún circunstancial, antepuesto o pospuesto al predicado, con el papel semántico de loc. temporal o espacial (v. g. Nos anos cincuenta en Santiago ía máis frío), modo, cuantificación (v. g. Vai moitísima calor), causa... Tampoco resulta infrecuente un dativo, en ocasiones de solidaridad (v. g. Vaiche moito frío).

La construcción es de cero participantes. Se usa en P3 y no admite se. Los valores aspectuales son dinámico, atélico, a veces progresivo inceptivo, medio o terminativo (v. g. Empeza a ir calor; está indo calor; deixou de ir calor), intensivo (v. g. Vai un diazo).

Las lenguas vecinas tienen estructuras similares: español (v. g. A veces hace frío), portugués (v. g. Ás vezes faz frio).

\subsection{Ir como predicado de estado}

Son construcciones de dos papeles semánticos, que reflejan estado propiamente dicho o subclases de estado como situación, caracterización, a veces producción de efecto. Los sujetos de estas construcciones tienen los respectivos papeles semánticos de portador de estado, situado, caracterizado, productor de efecto.

\section{Tener algo un determinado valor 0 coste}

52. o quilo vai a dúas mil, non é coma o pulpo que o quilo vai a quinientas (CANGASPontevedra, 14)

53. ;O grande, eh! Que ten ido hasta catrocentas e pico (CANGAS-Pontevedra, 14)

Esquema sintáctico sujeto-predicado-circunstancial. Esquema semántico portador de estado-estado-cuantificación.

Sujeto preverbal o posverbal cuando se pone énfasis en el verbo predicado (v. g. O quilo vai a trinta euros/vai a trinta euros o quilo/vai o quilo a trinta euros). Funciona como tal generalmente una fr. nom. definida en singular del tipo de o quilo, o prezo (no es habitual escuchar ${ }^{*}$ os quilos de peixe van a vinte euros), si bien no son infrecuentes ejemplos como os coches non van moi baratos. Sus rasgos semánticos son [-animado], [+concreto], [+continuo], generalmente [+común], [-control].

La complementación es obligatoria. El circunstancial está desempeñado por una fr. prep. de estructura $a+$ numeral, que señala la distribución proporcional de una cantidad. Los valores aspectuales son estativo y atélico.

En las mismas construcciones, ir también puede equivaler a chegar, subir funcionando como complemento una fr. prep. introducida por $a$ o ata, que indica el límite final de un 
desplazamiento de carácter nocional. La estructura sintáctica se presenta como transitiva o causativa, con o sin determinante (v.g. O quilo de polbo vai alata os vinte euros $\rightarrow$ os vendedores subiron/fixeron subir o quilo de polbo alata os vinte euros). El esquema semántico es aquí afectado-acción [movimiento nocional ascendente]-meta, con los valores aspectuales dinámico, télico, progresivo. Frente a la estructura precedente, ahora la construcción admite se intensificando el valor ascendente de una cosa con la imposibilidad de controlarlo (v. g. O quilo vai ata vinte euros $\rightarrow$ o quilo vaise ata (os) vinte euros). Los valores aspectuales prototípicos son estativo, atélico. En esquemas de movimiento nocional el valor aspectual sería dinámico.

Se registra esta estructura en portugués (v.g. A inflação foi a $20 \%$ ao mês). El español prefiere construcciones con verbos como estar, llegar o ascender.

Encontrarse, estar, situarse en un lugar la cualidad o entidad que se indica

54. a mellor fermosura é a que vai por dentro (RIBEIRA-A Coruña, 55)

55. ¿onde vai o respeto de antes? (LUGO, 60)

Esquema sintáctico sujeto-predicado-circunstancial. Esquema semántico situado-situaciónlocación espacial.

Sujeto preverbal; posverbal cuando el emisor centra la atención en el complemento o en la situación designada por el verbo predicado (v. g. Vai por dentro a mellor fermosura). Sus rasgos semánticos son [-animado], [-concreto], generalmente [+común], [-control].

La complementación es obligatoria. Acostumbra a funcionar una fr. adv., que indica la situación de una cualidad o de otra entidad abstracta.

La construcción es activa, de estado o situación. Se usa en P3 singular o plural y no admite se. Los valores aspectuales son estativo, atélico.

Ser una cualidad, hábito, modo de ser, propiedad, etc. característicos de alguien

56. non creo que lle inflúa moito, eso máis ben vai en cada persona (OURENSE, 25)

57. chegar tarde é algo que vai moito con el (LOUREIRO-Cotobade-Pontevedra, 80)

58. sempre foi moi formal e vai na súa maneira de ser (COVAS-Forcarei-Pontevedra, 70)

59. Vai vello e pensa no máis alá (COVAS-Forcarei-Pontevedra, 70)

Esquema sintáctico sujeto-predicado-circunstancial, sujeto-predicado-atributo. Esquema semántico respectivo situado-situación-loc. espacial, caracterizado-caracterizacióncaracterizador.

Sujeto preverbal. Está representado por una fr. nom. no definida o por una cláusula de infinitivo. Cuando remite a un nombre presenta los rasgos semánticos [-animado], [-concreto] aludiendo a entidades abstractas (actitudes, cualidades, comportamientos), con frecuencia [+común], [-control].

La complementación resulta obligatoria. El atributo puede estar representado por una frase adjetiva, que caracteriza la entidad en función de sujeto; el circunstancial está desempeñado por una fr. prep. de estructura con, en+fr.nom., con un referente que es una entidad de rasgos semánticos [+animado], [+concreto], que en este caso de la frase preposicional además de situar actúa a modo de entidad caracterizada, invirtiendo el orden habitual que posiciona al caracterizador pospuesto al predicado y al caracterizado en el sujeto. Cuando el referente de la fr. prep. es un nombre humano y definido se prefiere con a en (v. g. Iso vai moito con el; iso vai moito con Manolo/? iso vai moito nel/ ${ }^{*}$ iso vai moito en Manolo).

La construcción es activa, de tipo atributivo. Se usa en P3 singular o plural y no admite se. Los valores aspectuales son estativo, atélico.

Puede registrarse en español (v.g. Eso no va con nosotros). 
Ocupar un espacio físico o temporal entre dos puntos, extenderse, conducir

60. taban os guindiyas esperándonos al son dun zarro no camín que vai para Nunide (OSCOS-Asturias)

61. e nos meses que van de maio a ajosto non fai mal o sol (VILAGARCÍA-Pontevedra, 40)

Esquema sintáctico sujeto-predicado-circunstancial. Esquema semántico situado-situaciónloc. espacial o temporal/dirección.

Sujeto preverbal, posverbal cuando el emisor centra su atención en la situación o en un complemento. Sus rasgos semánticos son [-animado], [+concreto], [-concreto] en casos como (v. g. O tempo que vai entre o inverno e o verán...), [-control].

La complementación es obligatoria. Funciona un circunstancial que designa tanto extensión espacial o temporal como dirección, esta última mediante una fr. prep. de estructura $a$, para+fr.nom. Las dos preposiciones marcan un punto físico como límite de un espacio, y también pueden presentar algunas diferencias en cuanto a mayor o menor concreción de ese punto límite, esto es, a estrada que vai ao peirao conduce hasta el mismo puerto y puede rematar ahí, pero a estrada que vai para o peirao indica que va en dirección al puerto, aunque no tiene por qué terminar ni pasar necesariamente por dicho puerto sino que puede pasar por las proximidades. El complemento con valor temporal es una fr. prep. introducida por de, entre (menos frecuente) que limita un espacio determinado de tiempo entre dos puntos dados.

La construcción es activa, de estado. No admite se y se usa en P3 singular o plural. Los valores aspectuales son estativo, atélico.

El español y el portugués también conocen esta estructura (v. g. La carretera va desde aquí hasta la montaña; o caminho vai ao cimo da montanha; a conversa foi pela madrugada adentro).

\section{Manifestar inclinación por algo o alguien, gustar}

62. decían que ó médico lle iban as mulleres (COVAS-Forcarei-Pontevedra, 64)

63. vaille bastante o alcohol a Manuel (LALÍN-Pontevedra, 70)

Esquema sintáctico sujeto-predicado-compl. indirecto. Esquema semántico productor de efecto $^{8}$-producción de efecto-afectado.

Sujeto pospuesto, favorecido por el semantismo de la construcción y por la presencia de dativo. Puede estar representado por un nombre con los rasgos semánticos [+animado], [+concreto], generalmente [+común], [-control]; también puede ser una cláusula de infinitivo o introducida por que (v.g. Vaille facer bromas, pero non lle vai que llas fagan), reflejando así un evento.

La complementación resulta obligatoria. El complemento directo es un pronombre dativo y/o una fr. prep. de estructura $a+f$ fr.nom., con un referente [+humano] que señala el individuo portador de una afección. De forma opcional, se registra algún circunstancial con el papel semántico sobre todo de loc. temporal o espacial, cuantificación, modo, causa, fin (v.g. Agora por causa da timidez vaille moito beber para a súa diversión).

La construcción es activa, se usa en P3 singular o plural y no admite se. Los valores aspectuales son estativo, atélico; a veces habitual e intensivo.

En lenguas próximas como español puede documentarse (v.g. No le va el alcohol). El portugués prefiere la construcción con gostar de, combinar com.

\footnotetext{
8 Productor de efecto es el papel semántico referido a la entidad o individuo que produce en algo o en alguien un efecto, resultado o impresión. Puede funcionar en esquemas dinámicos o de estado.
} 


\subsection{Ir como predicado de proceso}

Aunque existen construcciones con este verbo que pueden transmitir proceso motivado por factores gramaticales (adverbios, verbo en gerundio...), las estructuras con ir no ofrecen demasiados casos de esquemas que reflejen proceso como valor primario.

\section{Desarrollarse, evolucionar de una determinada manera}

64. ¿como van os estudios? (GDXL, 1132)

\section{Esquema sintáctico sujeto-predicado-circunstancial. Esquema semántico experimentante- proceso continuativo/modificativo-modo.}

Sujeto preverbal. Puede posponerse debido a la modalidad interrogativa de la cláusula o al hecho de querer priorizar otra información distinta de la referida en el sujeto. Sus rasgos semánticos son [+animado], [+concreto], [+común], [-control].

La complementación es obligatoria. El circunstancial está representado por una frase adverbial que señala la manera de estar o de desarrollarse un individuo o una entidad. Opcionalmente puede acompañar un dativo con el papel semántico de afectado y a veces poseedor (v.g. A María vaille ben o brazo), y un circunstancial con diversos papeles semánticos como loc. temporal (v.g. Daquela íanme ben os estudos), causa (v. g. Os estudos vanche mal pola túa preguiza), condición (v.g. Coa túa axuda os estudos iríanme ben), concesión (v. g. Mesmo coa túa axuda non me irían ben os estudos)...

La construcción es de valor medio. Admite se y sujeto animado para indicar indeterminación (v. g. Se se vai ben hai que volver ao traballo). Los valores aspectuales son dinámico, atélico.

Esta estructura se encuentra en español y en portugués (v. g. ¿Como van los estudios?; Como vão as obras do novo hospital?; fizeram seu rosto ir do rubro ao branco).

\subsection{Ir como predicado de relación}

Son construcciones sobre todo de dos participantes. La complementación se concreta en la función sintáctica complemento prepositivo ${ }^{9}$ y en el papel semántico término ${ }^{10}$. Los esquemas

\footnotetext{
${ }^{9}$ Llamamos complemento prepositivo, también conocido por complemento preposicional, a la función sintáctica constituida formalmente por una frase preposicional introducida por preposiciones como a, con, de, en, por, sobre... En algunas estructuras aparece sólo una de ellas, lo que significa que el trueque de preposición implicará un cambio semántico y de construcción o de predicado, en otras es posible la alternancia, expresando significados muy próximos. El complemento prepositivo suele ser una función de presencia obligatoria debido a que su conmutación por cero convierte la construcción en agramatical o le hace variar el contenido. En algunos casos la ausencia formal de esta función no revela presencia cero sino latencia y puede ser reconocida a través del contexto o de la realidad externa al mensaje. En líneas generales, la relación del complemento prepositivo con el verbo en función de predicado es menos inmediata que la que demuestra el complemento directo con su predicado. El complemento prepositivo está algo más distante del predicado que el directo en el sentido de verse menos afectado en su totalidad (v.g. Sabe de matemáticas [afección parcial]/sabe matemáticas [afección total]. En palabras de Lazard (2002: 158), la diferencia entre la construcción directa (v. g. to shoot a rabbit; travailler sa thèse) y la oblicua está en el hecho de que la oblicua indica una acción "less clearly successful" y "suggests a conative action rather than an effective one or less direct effect on the patient". Además de esto, el complemento prepositivo va siempre introducido por una preposición que a veces varía según la construcción de que se trate y que introduce generalmente algún matiz de contenido -las formas gramaticales pocas veces son sinónimas-, mientras que el complemento directo o no lleva preposición o sólo a y alguna otra en determinados casos (en francés por ejemplo $a$ o de); el compl. prepositivo suele presentar valor aspectual atélico mientras que el directo tiende a manifestar valores télicos; el complemento prepositivo se conmuta por un pronombre precedido de preposición y el directo lo hace por un clítico de acusativo.

${ }^{10}$ Utilizamos la etiqueta término para hacer referencia a la entidad animada o inanimada en la que desemboca, se proyecta o converge cualquier tipo de evento, incluido el derivado de esquemas de relación (v. g. Tratar con alguén/alguien). Es un papel semántico que asociamos a la función sintáctica compl. prepositivo, a pesar de que esta función puede desempeñar también algún otro papel semántico.
} 
de relación con este y con otros verbos pueden solaparse o discurrir paralelos a acciones o a estados.

Participar, relacionarse, asociarse con alguien en un trabajo, juego, etc.

65. estaba en Televés, el iba comigo neste tema e tal (SANTIAGO, 40)

66. xogando ó tute gustábame moito ir co papá porque ganabamos sempre (COVAS-

FORCAREI-Pontevedra, 64)

Esquema sintáctico sujeto-predicado-complemento prepositivo. Esquema semántico portador de relación-relación-término.

Sujeto preverbal. Sus rasgos semánticos son [+humano], [+concreto], [+común], [+control].

La complementación es obligatoria. El complemento prepositivo está representado por una fr. prep. de estructura con+fr.nom., con referente [+animado] y [+común], que señala el individuo que se relaciona o participa con otro en algo. Opcionalmente puede acompañar un circunstancial con el papel semántico de cuantificación, causa (v. g. Daquela ía moito comigo nese tema por interese), modo, fin, loc. temporal o espacial, condición (v. g. Sen a túa axuda non iría comigo nese tema), concesión (v. g. Mesmo coa túa axuda non iría comigo nese tema)...

La construcción es activa. Admite se para indicar sujeto indeterminado. Los valores aspectuales son dinámico, atélico, a veces intensivo.

Alguna de estas construcciones también se documenta en español (v.g. Va con el primero que llega) y en portugués (v. g. Ir na conversa de alguém e lamenta-lo; nunca fomos um com o outro; vai com o primeiro que aparece).

\section{Combinar una cosa con otra}

67. a blusa non vai con esa saia (ACIVEIRO-Forcarei-Pontevedra, 32)

68. o negro vai con moitas cousas (LOUREIRO-Cotobade-Pontevedra, 34))

Esquema sintáctico sujeto-predicado, sujeto-predicado-compl. prepositivo. Esquema semántico portador de relación-relación, portador de relación-relación-término.

Sujeto preverbal. Alude preferentemente a colores o prendas de vestir. Sus rasgos semánticos son [-animado], generalmente [+concreto] y [+común], [-control].

La complementación es cero cuando el sujeto es plural o compuesto, aglutinando las dos unidades puestas en relación (v.g. O verde $e$ o vermello non van). En las restantes construcciones funciona un complemento prepositivo, que es una fr. prep. de estructura con+fr.nom., con un referente [-animado] que indica el segundo miembro de la relación establecida entre dos entidades ( $\mathrm{X}$ con $\mathrm{Z}$ ). Con frecuencia acompaña un circunstancial representado por una fr. adv. con el papel semántico de modo (v. g. O cinto vai ben con eses zapatos), o un pronombre dativo señalando la persona a quien se le aplica lo designado en la relación (v.g. O pantalón no lle vai ben coa chaqueta).

La construcción es activa, de estado. Se usa en P3 singular o plural. Estas construcciones muestran una relación simétrica entre un designado y un referente, pudiendo trocar las respectivas unidades sintácticas su correspondiente lugar sin que el esquema varíe, aunque sí cambiaría el tipo de información transmitido, de acuerdo con la unidad que se tome como punto de partida (v. g. A blusa vai coa saia/a saia vai coa blusa). Frente a las estructuras de complemento prepositivo en las que sólo la entidad designada por el sujeto se somete a contraste, otras documentadas, sobre todo con negación, presentan los dos elementos relacionados simultáneamente dentro de una estructura coordinada que funciona como sujeto de un predicado monovalente (v. g. O negro e o branco non van).

Los valores aspectuales son estativo, atélico. 
En lenguas próximas como español y portugués se registra esta estructura (v.g. El rojo va bien con el negro; $O$ amarelo não vai com o verde).

\subsection{Ir como predicado de actitud}

Son pocas las construcciones que comprende esta subclase semántica que llamamos actitud o actitud/conducta. Se trata de estructuras de dos participantes, en las que la actitud/conducta se superpone a algún tipo de acción o estado, según los casos.

Adoptar una determinada actitud o modo de actuar

69. Vai de chulo (COVAS-Forcarei-Pontevedra, 34)

70. Vas de rico galán, pero non enganas (SANTIAGO, 35)

Esquema sintáctico sujeto-predicado-complemento prepositivo. Esquema semántico portador de actitud/conducta-actitud/conducta-término.

Sujeto preverbal. Sus rasgos semánticos son [+humano], [+concreto], [+común], [+control].

La complementación es obligatoria. El complemento prepositivo está representado por una fr. prep., de estructura de+fr.nom., con un referente de rasgos semánticos [-animado], [concreto], en general [+continuo], que muestra la forma de actuar de un individuo. En ocasiones puede acompañar algún circunstancial con papeles semánticos como loc. espacial o temporal, fin, causa (v.g. Agora vai de guapo por ligar), sustitución (v.g. Vai de rico en lugar de persoa humilde), adición (v. g. Ademais de rica vai de guapa)...

La construcción es activa, con sujeto de cierto carácter agentivo, que traduce una determinada disposición anímica con proyección exterior, concretada en un modo de actuar; también se refleja implícitamente una determinada caracterización de alguien. Admite se para indicar sujeto indeterminado. Los valores aspectuales son dinámico, atélico.

Lenguas próximas como el español tienen estructuras parecidas (v. g. ¿ahora vas de guapo?), no así el portugués (v. g. Se faz de bonito).

\section{$5 \quad$ Conclusión}

Hemos presentado una propuesta de diccionario de construcciones con el fin de demostrar que ofrece amplia información de carácter gramatical, que puede satisfacer las necesidades de diferentes tipos de usuarios.

Por lo que respecta a las construcciones con ir, con las que ilustramos este prototipo de diccionario, podemos remarcar su carácter diverso y transversal en cuanto a contenidos, valores y esquemas semánticos.

Aunque las construcciones más representativas son las de acción con movimiento, a veces este significado primario de movimiento se diluye en diferentes contenidos y esquemas que transmiten estado (concretado por veces en situación y caracterización), proceso, relación y actitud/conducta.

En cuanto a los esquemas sintácticos, observamos que los más usuales son los de sujetopredicado-circunstancial y sujeto-predicado, le siguen sujeto-predicado-complemento prepositivo, sujeto-predicado-complemento indirecto, sujeto-predicado-atributo y únicamente predicado. Los esquemas semánticos demuestran su diversidad en la siguiente clasificación:

- De cero participantes: acción meteorológica.

- De un participante: agente-acción; afectado-acción; portador de relación-relación.

- De dos participantes: agente-acción-dirección/destino; agente-acción-modo; agente-acción-medio; agente-acción-locación espacial/tránsito; agente-accióntérmino; afectado-acción-destino; experimentante-proceso modificativo-modo; 


\section{productor de efecto-producción de efecto-afectado; portador de estado-estado- cuantificación; portador de actitud-actitud-término; portador de relación- relación-término; caracterizado-caracterización-caracterizador; situado- situación-loc.espacial/temporal.}

El sujeto se sitúa mayoritariamente en posición preverbal, como es de regla en las lenguas romances. Con todo existen aquí muchos sujetos (sobre el 28\%) que pueden seguir al predicado motivado por rasgos de tipo informativo, ausencia de animación y control del sujeto, presencia de se y dativo así como por el semantismo de ciertas construcciones. El carácter animado del sujeto sobresale frente a la no animación (40\%). Para el rasgo de control, los datos son muy similares, con leve ventaja (en torno al 46\%) para las muestras cuyo sujeto presenta [+control].

Entre los valores aspectuales priman los contenidos de dinamicidad sobre los de estatividad.

Hemos visto que ciertas construcciones del gallego muestran equivalencias con lenguas peninsulares próximas, como español y portugués; en cambio otras no encuentran correspondencia o presentan divergencias estructurales.

Por último, los datos expuestos confirman que ir es un predicado que no se somete a una única clase semántica, no puede limitarse a la convencional calificación de verbo de acción y movimiento, dado que participa en construcciones de carácter transversal y poliédrico en cuanto a significado y estructura. De ahí que resulte reduccionista, aunque práctico, el hecho de establecer clasificaciones de los verbos a modo de clases semánticas independientes: verbos de acción, de estado, de proceso, de movimiento, de sentimiento... (Levin 1993: 111276).

Sobre los papeles semánticos hemos de comentar, desde una perspectiva general, que aunque su taxonomía es finita, una postura maximalista como la que seguimos permite encajarlos en sus construcciones respectivas con mayor rigor y concreción. De ahí que la rentabilidad del uso de papeles, no muy comunes, como los utilizados (portador de actitud/conducta, portador de relación, portador de estado) sirva para encauzar con más grado de precisión la polisemia asociada a cada verbo y a cada construcción.

\section{Fuentes primarias}

Alonso, Dámaso (1972): "Narraciones orales gallego-asturianas. San Martín de Oscos". In: Obras completas. I. Estudios lingüísticos peninsulares. Madrid, Gredos: 495-521. (= OSCOS).

Cabana, Darío X. (1994): O cervo na torre. Vigo: Xerais. (= OCT).

Carballeira, Xosé María (ed.) (2000): Gran diccionario Xerais da lingua. Vigo: Edicións Xerais de Galicia. (= GDXL).

Casares, Carlos (1998): Deus sentado nun sillón azul. Vigo: Galaxia. (= DEUS).

Méndez Ferrín, Xosé Luís (1987): Bretaña, Esmeraldina. Vigo: Xerais (= BE).

Méndez Ferrín, Xosé Luís (1991): Arraianos. Vigo: Xerais (= ARR).

Rivas, Manuel ( $\left.{ }^{3} 1995\right)$ : En salvaxe compaña. Vigo: Xerais. (= ESC).

Santamarina, Antón (ed.) (2011): Tesouro informatizado da lingua galega. Santiago de Compostela: USC/Instituto da Lingua Galega. http://www.ti.usc.es/TILG/, consultado 8 de diciembre, 2012.

Soto Andión, Xosé (1993-2000): Gravacións (60 horas). Material inédito transcrito procedente de diferentes puntos de Galicia. Santiago de Compostela.

Vázquez-Monxardín, Afonso (ed.) (1992): A cultura popular de tradición oral nos centros da terceira idade. Unha experiencia de recollida en centros de Ourense, Santiago, Tui e Viveiro. Santiago de Compostela: Consello da Cultura Galega. 
Vidal, Ana (1994): Contribución ó estudio do léxico de Loureiro (Cotobade). Santiago de Compostela: Universidade de Santiago. Tese de licenciatura inédita.

\section{Fuentes secundarias}

Ackema, Peter/Schoorlemmer, Maaike (2006): "Middles". In: Martin Everaert/Henk van Riemsdijk (eds.) (2006): The Blackwell Companion to Syntax. Oxford, Blackwell: 131203.

Alexiadou, Artemis/Anagnostopoulou, Elena/Everaert, Martin (eds.) (2003): The unaccusativity puzzle: explorations of the syntax-lexicon interface. Oxford: Oxford University Press.

Álvarez, Rosario/Xove, Xosé (2002): Gramática da lingua galega. Vigo: Galaxia.

Azorín Fernández, Dolores (2003): "La lexicografía como disciplina lingüística". In: Medina, Antonia María (ed.) (2003): Lexicografía española. Barcelona, Ariel: 31-52.

Baltin, Mark R. (2003): "A-movements". In: Baltin, Martin/Collins, Chris (eds.) (2003): The Handbook of Contemporary Syntactic Theory. Oxford, Blackwell: 226-254.

Bertinetto, Pier Marco/Delfitto, Denis (2000): "Aspect vs. Actionality: why they should be kept apart". In: Dahl, Östen (ed.) (2000): Tense and aspect in the languages of Europe, Berlin/New York, de Gruyter: 189-226.

Busse, Winfried/Dubost, Jean-Pierre (1983): Französisches Verblexikon. Stuttgart: Klett.

Busse, Winfried (ed.) (1994): Dicionário sintáctico de verbos portugueses. Coimbra: livraria Almedina.

Carpenter, Bob (1997): Type-logical semantics grammar. Cambridge (Massachusetts): MIT.

Cidrás, Francisco A. (1991): "As construccións pronominais en galego. Proposta de clasificación e caracterización". In: Brea, Mercedes/Fernàndez Rei, Francisco (eds.) (1991): Homenaxe ó profesor Constantino García. Santiago de Compostela, Universidade de Santiago: 101-125.

Cifuentes Honrubia, José Luis (1999): Sintaxis y semántica del movimiento, aspectos de gramática cognitiva. Alicante: Instituto de Cultura Juan Gil Albert.

Comrie, Bernard (2008): "What is passive?" In: Estrada, Zarina et al. (eds.) (2008): Studies in voice and transitivity. Munich, Lincom: 1-18.

Crego, María Victorina (2000): El complemento locativo en español. Los verbos de movimiento y su combinatoria sintáctico-semántica. Santiago de Compostela: Universidade de Santiago.

Cuervo, Rufino José (1886-1893): Diccionario de construcción y régimen de la lengua castellana. Bogotá. Reimpresión do Instituto Caro y Cuervo, 1953.

Dik, Simon C. (1997): The Theory of Functional Grammar. Berlin: Mouton de Gruyter.

Dimitrova-Vulchanova, Mila (1999): Verb semantics, diathesis and aspect. München: Lincom.

Fillmore, Charles (2006): "Frame Semantics". In: Geeraerts, Dirk (ed.) (2006): Cognitive Linguistics. Basic Readings. Berlin/New York, De Gruyter: 273-400.

Garrudo, Francisco (1991-1996): Diccionario sintáctico del verbo inglés. Barcelona: Ariel.

Goldberg, Adele E. (1995): Constructions. A Construction Grammar Approach to Argument Structure. Chicago: Chicago University Press.

Goldberg, Adele E. (2006): Constructions at Work: The Nature of Generalization in Language. Oxford: Oxford University Press.

Halliday, Michael Alexander K. (1967): "Notes on transitivity and theme". Journal of Linguistics 3: 37-81.

Halliday, Michael Alexander K. (1994): An Introduction to Functional Grammar. London: Arnold.

Halliday, Michael Alexander K./Mathiessen, Christian (2004): An Introduction to Functional Grammar. London: Arnold. 
Helbig, Gerhard/Schenkel, Wolfgang (1991): Wörterbuch zur Valenz und Distribution deutscher Verben. Tübingen: Niemeyer.

Herbst, Thomas et al. (2004): A Valency Dictionary of English: A corpus based analysis of the complementation patterns of English verbs, nouns and adjectives. Berlin: De Gruyter.

Hopper, Paul, J./Sandra A. Thompson (1980): "Transitivity in grammar and discourse". Language 56, 2: 251-299.

Jackendoff, Ray S. (2007): Semantic Structures. Cambridge/Massachussets: MIT.

Janda, Laura A./Lyashevskaya, Olga (2011): "Grammatical profiles and the interaction of the lexicon with aspect, tense and mood in Russian". Cognitive Linguistics 22, 4: 719-763.

Lamiroy, Beatrice/Delbecque, Nicole (1998): "The possessive dative in Romance and Germanic languages". In: Van Langendonck, Willy/Van Belle, William (eds.) (1998): The dative II. Amsterdam, John Benjamins: 29-74.

Landau, Idan (1999): "Psych-adjectives and semantic selection". The Linguistic Review 16, 4: 333-358.

Langacker, Ronald W. (2008): Cognitive Grammar. A basic introduction. Oxford: Oxford University Press.

Lazard, Gilbert (2002): "Transitivity revisited as an example of a more strict approach in typological research". Folia linguistica XXXVI, 3-4: 141-190.

Levin, Beth (1993): English Verb Classes and Alternations. Chicago, University of Chicago Press: 111-276.

Luque, Juan de Dios (2001): Aspectos universales y particulares del léxico de las lenguas del mundo. Granada: Granada Lingvistica.

Mendikoetxea, Amaya (1999): "Construcciones con se: medias, pasivas e impersonales". In: Bosque, Ignacio/Demonte, Violeta (ed.) (1999): Gramática descriptiva de la lengua española. Madrid, Real Academia Española/Espasa Calpe: 1631-1722.

Miguel, Elena De (1999): "El aspecto léxico". In: Bosque, Ignacio/Demonte, Violeta (ed.) (1999): Gramática descriptiva de la lengua española. Madrid, Real Academia Española/Espasa Calpe: 2977-3060.

Moreno Cabrera, Juan Carlos (2003): Semántica y gramática.Sucesos, papeles semánticos y relaciones sintácticas. Madrid: Machado Libros.

Morimoto, Yuko (2001): Los verbos de movimiento. Madrid: Visor.

Perloff, Richard M. (2003): The Dynamics of Persuasion. Communication and Attitudes in the 21st Century. 4th edition. New Jersey: LEA.

Primus, Beatrice (1999): Cases and Thematic Roles. Tübingen: Niemeyer.

Real Academia Galega (2012): Diccionario da Real Academia Galega. A Coruña: RAG. http://www.realacademiagalega.org, consultado 8 de diciembre, 2012.

Rey-Debove, Josette/Rey, Alain (2006): Le Petit Robert. Paris: Dictionnaires Le Robert.

Ritter, Elizabeth/Rosen, Sara T. (2000): "Event structure and ergativity". In: Pustejovsky, James/Tenny, Carol (eds:) (2000): Events as grammatical objects. Stanford, CSLI: 187237.

Riveiro, Xesús (2002): Diccionario cumio de construccións preposicionais. Vigo: Edicións do Cumio.

Rothstein, Susan (2004): Structuring Events. Oxford: Blackwell.

Sánchez López, Cristina (ed.) (2002): Las construcciones con se. Madrid: Visor.

Schumacher, Helmut (ed.) (1986): Verben in Feldern. Valenzwörterbuch zur Syntax und Semantik deutscher Verben. Berlin/New York: de Gruyter.

Schumacher, Helmut et al. (2004): Valenzwörterbuch deutscher Verben. Tübingen: Narr.

Seco, Manuel (1995): "La microestructura del diccionario del español actual". Cadernos de lingua 3: 25-47.

Seco, Manuel (ed.) (1999): Diccionario de español actual. Madrid: Aguilar. 
Slobin, Dan (2004): "The Many Ways to Search for a Frog: Linguistic Typology and the Expression of Motion Events". In: Strömqvist, Sven/Verhoeven, Ludo (eds.) (2004): Relating Events in Narrative: Typological and Contextual Perspectives. Mahwah, Lawrence Erlbaum: 219-257.

Slobin, Dan (2006): "What makes manner of motion salient? Explorations in linguistic typology, discourse, and cognition". In: Hickmann, Maya/Robert, Stephane (eds.) (2006): Space in Languages: Linguistic Systems and Cognitive Categories. Amsterdam, John Benjamins: 59-81.

Soanes, Catherine/Stevenson, Angus (eds.) (2005): Oxford Dictionary of English. Oxford: Oxford Universtiy Press.

Soto Andión, Xosé (2005): "Construcións intransitivas de actitude e conduta en galego". Vox Romanica 64: 171-202.

Soto Andión, Xosé (2008): "Esquemas intransitivos con Dar en gallego: variación semántica y combinatoria sintáctica". Revue Roumaine de Linguistique LIII, 4: 405-425.

Soto Andión, Xosé (2010a): "Structures with Saír in Galician". Modern Language Review 105, 2: 411-438.

Soto Andión, Xosé (2010b): "La semántica de pasar: análisis y variación". Zeitschrift für romanische Philologie 126, 3: 480-513.

Soto Andión, Xosé (2011): "La semántica de los estados en gallego". Neuphilologische Mitteilungen CXII, 3: 323-363.

Talmy, Leonard (1985): "Lexicalization patterns: semantic structure in lexical forms". In: Shopen, Timothy (ed.) (1985): Language typology and syntactic description. Cambridge: Cambridge University Press.

Talmy, Leonard (2000): Toward a Cognitive Semantics. Typology and Process in Concept Structuring. Vol. 2. Cambridge: MIT Press.

Tesnière, Lucien $\left({ }^{2} 1969\right)$ : Éléments de syntaxe structurale. Paris: Klincksieck.

Thieroff, Rolf (2000): "On the areal distribution of tense-aspect categories in Europe". In: Dahl, Östen (ed.) (2000): Tense and aspect in the languages of Europe. Berlin/New York, de Gruyter: 265-305.

Van Valin, Robert D./Lapolla, Randy J. (1997): Syntax. Structure, Meaning and Function. Cambridge: Cambridge University Press.

Van Valin, Robert D. (2005): Exploring the Syntax-Semantics Interface. Cambridge: Cambridge University Press. 